\title{
Assessment of medical intern's knowledge, awareness and practice of familial hypercholesterolemia at academic institutes in Jeddah, Saudi Arabia
}

\author{
Sami H. Alzahrani ${ }^{1 *}$ (D, Abdulhadi Bima², Mohammed R. Algethami ${ }^{3}$ and Zuhier Awan²
}

\begin{abstract}
Background: Familial Hypercholesterolemia $(\mathrm{FH})$ is a serious under-diagnosed disease characterized by raised lowdensity lipoprotein cholesterol (LDL-C) and premature coronary artery diseases (CAD). The scarcity of FH reported patients in Saudi Arabia indicates lack of FH awareness among physicians.

Objective: The goal of this research was to assess knowledge, awareness, and practice (KAP) about FH disorder among Saudi medical interns and to identify areas that need educational attention.

Methods: This cross-sectional study involved 170 Saudi medical interns ( 83 males and 87 females) from academic institutes in Jeddah, Saudi Arabia. The interns were asked to fill an online FH-KAP questionnaire. Total score for each separate domain measured by adding correct answers.

Results: Although, knowledge of FH definition (76.5\%) and classical lipid profile (52.4\%) were reasonable; knowledge on inheritance (43.5\%), prevalence (12.4\%) and CAD risks (7.1\%) were poor. Knowledge score was significantly higher in female than male $(7.5 \pm 3$ vs. $5.3 \pm 2.6, P<0.001)$. Regarding awareness, $54.1 \%$ were familiar with $\mathrm{FH}$ disorder, $50.6 \%$ with the presence of lipid clinic but only $16.5 \%$ were acquainted with guidelines. Furthermore, in the practice domain $82.9 \%$ selected statin as first line treatment and $62.9 \%$ chose routinely checking the rest of the family, while 15.3\% chose ages 13-18 years to screen for hypercholesterolemia in patients with a positive family history of premature CAD.
\end{abstract}

Conclusion: Substantial defects in FH-KAP among Saudi medical interns were found, emphasizing the importance of professional training. Extensive and constant medical education programs as early as an internship are required to close the gap in CAD prevention.

Keywords: Cardiovascular diseases, Familial hypercholesterolemia, Medical intern, Knowledge, Awareness, Practices, Gender

\footnotetext{
* Correspondence: drsamihz@gmail.com

${ }^{1}$ Family Medicine Department, Faculty of Medicine, King Abdulaziz University, PO Box 80205, Jeddah 21589, Saudi Arabia

Full list of author information is available at the end of the article
}

C C The Author(s). 2020 Open Access This article is licensed under a Creative Commons Attribution 4.0 International License, which permits use, sharing, adaptation, distribution and reproduction in any medium or format, as long as you give appropriate credit to the original author(s) and the source, provide a link to the Creative Commons licence, and indicate if changes were made. The images or other third party material in this article are included in the article's Creative Commons licence, unless indicated otherwise in a credit line to the material. If material is not included in the article's Creative Commons licence and your intended use is not permitted by statutory regulation or exceeds the permitted use, you will need to obtain permission directly from the copyright holder. To view a copy of this licence, visit http://creativecommons.org/licenses/by/4.0/ The Creative Commons Public Domain Dedication waiver (http://creativecommons.org/publicdomain/zero/1.0/) applies to the data made available in this article, unless otherwise stated in a credit line to the data. 


\section{Introduction}

Since Muller described, back in 1938, xanthomas collections, raised serum cholesterol and myocardial infarction (MI) [1] and later in the 1970s Brown and Goldstein reported the defects in the low-density lipoprotein receptor (LDLR) as the etiology of familial hypercholesterolemia $(\mathrm{FH})$ [2], our understanding of $\mathrm{FH}$ has grown tremendously. Familial hypercholesterolemia is a classical monogenic worldwide health disturbance of lipoprotein metabolism manifested by raised serum values of low-density lipoprotein cholesterol (LDL-C) since birth $[2,3]$. FH is inherited mainly as an autosomal dominant (AD), but it can also be inherited as an autosomal recessive (AR) pattern. Mutation in one or more genes leads to $\mathrm{FH}$. The well-known AD genes are: low-density lipoprotein receptor $(L D L R)$ [2], proprotein convertase subtilisin/ Kexin type 9 (PCSK9) [4], and apolipoprotein B$100(A P O B)[5]$. Alteration in one allele of the abovementioned genes leads to heterozygous $\mathrm{FH}(\mathrm{HeFH})$ while alterations in two alleles cause the severe form of homozygous $\mathrm{FH}(\mathrm{HoFH})$. Alteration of LDL receptor adaptor protein 1 (LDLRAP1) gene leads to AR type [6]. If $\mathrm{FH}$ is left unmanaged, the occurrence of premature coronary artery diseases (CAD) in HoFH patients are definitive, meanwhile, $\mathrm{HeFH}$ patients carry a 50\% CAD hazard in men and $30 \%$ in women by 50 years [2]. The AR-type of $\mathrm{FH}$ is clinically similar to $\mathrm{HeFH}$ and $\mathrm{HoFH}$ with moderate elevations in LDL-C values if the two alleles were altered and the clue is the normal parents' lipid profile and the dramatic respond to lipiddecreasing modulates [7].

The estimated prevalence of $\mathrm{HeFH}$ is 1 in 200 to 500 in many populations [8-10]. with a prevalence of one $\mathrm{HoFH}$ in a million individuals [11]. Recent reported HeFH prevalence are 1 in 213, 250, 353 in China, United States and Australia, respectively [9, 10, 12] meanwhile, the problem magnitude is unsettled in the Middle East, including Saudi Arabia [13]. There is an absence of genetic epidemiological research carried to determine $\mathrm{FH}$ prevalence in Saudi Arabia [14]. Depending on public census (http://www.stats.gov.sa/en/node), the expected FH prevalence in Saudi Arabia is between 63,485 to 158, 712 patients of $\mathrm{HeFH}$, depending on the rate of 1:200500. The true FH prevalence in Saudi Arabia and Middle East is hindered because of the absence of genetic screening programs and national records [14]. In comparison, three Western countries reported more than 500 gene mutations in $\mathrm{FH}$, while only fifty seven mutations were documented from seventeen Middle Eastern and North African (MENA) countries [15]. Although FH criteria is helpful, some practical limitation exists including lack of family history, clinical manifestations like corneal arcus, xanthelasmas, tendon xanthomas and DNA analysis. Furthermore, engaged clinical settings from primary to tertiary care, preoccupied by available beds and early discharge plans and fail to secure preventive measures to identify and follow-up $\mathrm{FH}$ patients [16]. These diagnosis complexities in addition to the high consanguinity rate in the Middle East inflates rates of FH under-reporting and under-management and indicates poor awareness of cardiovascular diseases (CVD) associated with $\mathrm{FH}[8]$.

A major debate in clinical practice these days is to elevate $\mathrm{FH}$ awareness between physicians so they might increase efforts to identify and treat these patients with intensive LDL-C-lowering drugs. Increasing $\mathrm{FH}$ awareness is very important, as most $\mathrm{FH}$ patients remain undetected. An additional problem is that current management of $\mathrm{FH}$ patients is often suboptimal and, even if treated with available lipid-lowering drugs, patients with $\mathrm{FH}$ still have considerably increased CVD mortality versus general population. Increased awareness and a wider urge to treat $\mathrm{FH}$ patients appropriately is required to decrease their high risk for premature chronic heart diseases and death [17]. For patients with severe familial hypercholesterolaemia, therapy should be beginning with ezetimibe and statins, and other conventional therapy. If treatment aims didn't get, new drugs (as PCSK9 suppressors, mipomersen and lomitapide) should be given [18].

The aim of this study was to assess knowledge, awareness, and practice (KAP) about FH disorder among Saudi medical physicians especially during their internship year, to detect if it provides them with good knowledge and practical skills to manage $\mathrm{FH}$ cases during their post-qualification.

\section{Methods \\ Study design and setting}

This cross-section, questionnaire-dependent work was carried among Saudi medical interns at two academic institutions: King Abdulaziz University and University of Jeddah, Saudi Arabia during the month of April 2019. This study was accepted by the biomedical ethical committee at the two universities and all doctors were notified about the research objectives. Written informed consent was optioned from participants before entering the research. Permission was taken from Sjouke et al. to use the questionnaire [19]. The questionnaire was validated and distributed as an electronic form. FH-KAP questionnaire validity was tested using PCPPG- Qual test [20] and reliability coefficient was tested using KR20 reliability coefficient [21]. The questionnaire is composed of two parts: the first one inquired about demographic characteristics and consists of 3 questions (age, gender, and GPA score) and the second part inquired about knowledge, awareness, and practice in $\mathrm{FH}$ 
(FH-KAP) disorder and consists of 20 items with a total of 38 marks.

\section{Study instrument}

The FH-KAP questionnaire utilized in this research was initially made by Bell et al. [22] It contained 20 items cover wide items of FH-KAP, 10 knowledge (17 marks), 5 awareness (13 marks) and 5 practices items ( 8 marks). These items found in many designs as single best answer question, 7-point Likert scale, dichotomous answers of 'Yes / No / Don't know', multiple answer questions, and make out answer statement. The participants asked to choose the right answer. They could select more than one answer in many questions. The FH questions evaluate participant's knowledge of $\mathrm{FH}$ as clinical properties, diagnostic lipid profile, mode of inheritance, prevalence, awareness of genetic cause for the diagnosis and relation of FH with CAD. Some sections assess intern's awareness of new guidelines, therapeutic alternatives and patients' treatment goals. They were also assessed for investigations that helped in screening for possible $\mathrm{FH}$ and reflect best medical practice in early detection.

\section{Questionnaire score}

The FH-KAP score was made according to a published study [23]. For determined FH familiarity, Likert-scale, a seven points scale in which one denotes "not at all familiar" and seven denotes "extremely familiar", results between 1 and 4 meant 'unfamiliar' and encoded ' 0 ', meanwhile results of 5-7 meant 'familiar' and encoded as ' 1 '. Incorrect answer encoded as ' 0 ', while right answer coded as ' 1 '. The questionnaire score was made by adding the right responses of all questions in each domain. Total score mark for every individual ranged from 0 to 19 for knowledge, $0-15$ for awareness, and 0-9 for practices. Each domain total scores range were un-similar with items numbers as some statements had more than one right answer. The mean of total KAP score of $\geq 50 \%$ for each domain was acceptable [24].

\section{Sample size calculation}

The numbers of medical interns at the two academic institutions in the year 2019 were 230 doctors. The sample size was made by RAOSOFT calculator (http://www.rao soft.com/samplesize.html), assuming $50 \%$ probability, 95\% confidence level, and 5\% sampling error. The minimum measured sample was 145. Presuming nonresponse rate of $15 \%$, the sample size was elevated to 170 . The sample was proportionally stratified based on gender.

\section{Subject recruitment and data collection}

One hundred and seventy out of 230 (73.9\%) Saudi medical interns at the two academic institutions completed the online survey and were recruited via simple random sampling by digits from doctors' names lists. Participants were screened for competence based on exclusion and inclusion criteria. Medical students from, general practicing (GP) and physicians were excluded. Eligible medical interns were asked to fill an online questionnaire in about fifteen minutes without returning to notes or online recourses. The completed sheet was returned to researchers for analysis.

\section{Statistical analysis}

Data analysis was done by SPSS software version 20 (SPSS Inc., Chicago, IL, USA). Categorical variables were reported as frequency and percentage (\%) and parametric parameters as mean $+/-$ standard deviation (SD) and minimum and maximum values. The Chi-Square test was used to evaluate the dissimilarity of correct answers between males and females. The normality of data was assessed by Shapiro- Wilk test, and accordingly, the total score for knowledge, awareness, and practice domains showed abnormal distribution, thus Mann Whitney test was utilized to differentiate mean scores between males and females. While the age was normally distributed so unpaired student "t" test was applied for comparison. A $P$-value of $<0.05$ indicated significant changes.

\section{Results}

\section{Demographic and practice details}

The sheets were given to 170 Saudi medical intern doctors, 83 (48.8\%) were males and $87(51.2 \%)$ were females. Their age ranges from 23 to 32 years old. The age of males was significantly higher than females $(P=0.0001)$. The GPA score of all participants is as the following: mostly $3.50-4.49$ (66.5\%), then $>4.50(23.5 \%)$ and lastly 2.50-3.49 (10.0\%). There were insignificant differences in the different grades of GPA scores between males and females (Table 1).

\section{Knowledge regarding $\mathrm{FH}$}

The numbers of correct answers to knowledge items are stratified to male and female and are shown in Table 2 . $100.0 \%$ of participants correctly answered that none of the features mentioned exclude FH diagnosis, $76.5 \%$ correctly defined $\mathrm{FH}, 52.4 \%$ correctly defined $\mathrm{FH}$ lipid profile, $45.9 \%$ correctly indicated that genetic evaluation is not needed for the right $\mathrm{FH}$ diagnosis, $43.5 \%$ correctly identified FH mode of inheritance, $12.4 \%$ correctly identified $\mathrm{FH}$ prevalence, $7.1 \%$ correctly identified CAD risk in $\mathrm{FH}$ and $4.7 \%$ correctly identify target LDL-C value in $\mathrm{FH}$. Regarding family history to be taken in $\mathrm{FH}, 62.4$ select onset age of premature CHD, 52.4\% select family history of hypercholesterolemia, $44.7 \%$ select family history of tendon xanthomata, $42.9 \%$ select family history of childhood unexplained death, $28.8 \%$ select the 
Table 1 Demographic characteristics of Saudi Medical interns $(n=170)$

\begin{tabular}{lllll}
\hline Characteristics & $\begin{array}{l}\text { Total } \\
(n=170)\end{array}$ & $\begin{array}{l}\text { Male } \\
(n=83,48.80 \%)\end{array}$ & $\begin{array}{l}\text { Female } \\
(n=87,51.20 \%)\end{array}$ \\
\hline Age (years) & $24.36 \pm 0.94$ & $24.70 \pm 1.07$ & $24.03 \pm 0.66$ \\
$(23.00-32.00)$ & $(23.00-32.00)$ & & \\
GPA & & & $23(26.00-27.00)$ & \\
$>4.50$ & $40(23.50 \%)$ & $17(20.50 \%)$ & $57(65.50 \%)$ & 0.0001 \\
$3.50-4.49$ & $113(66.50 \%)$ & $56(67.50 \%)$ & $7(8.00 \%)$ & 0.925 \\
$2.50-3.49$ & $17(10.00 \%)$ & $10(12.00 \%)$ & 0.467 \\
\hline
\end{tabular}

Data are expressed as mean+/- standard deviation (minimum - maximum) or number (\%) as appropriate. Comparison between male and female was made using Chi-Square test for non - parametric parameters and unpaired student " $\mathrm{t}$ " test for parametric parameters

Table 2 Comparison of overall correct responses in knowledge regarding FH between male and female Saudi medical interns. (10 questions, total score 17)

\begin{tabular}{|c|c|c|c|c|c|}
\hline No & Areas of KAP regarding $\mathrm{FH}$ being tested & $\begin{array}{l}\text { Total } \\
(n=170)\end{array}$ & $\begin{array}{l}\text { Male } \\
(n=83)\end{array}$ & $\begin{array}{l}\text { Female } \\
(n=87)\end{array}$ & $P$ value \\
\hline \multicolumn{6}{|c|}{ Knowledge items } \\
\hline 3 & Correctly defined FH & $130(76.50 \%)$ & $55(66.30 \%)$ & $75(86.20 \%)$ & 0.002 \\
\hline 4 & Correctly defined lipid profile of FH & $89(52.40 \%)$ & $27(32.50 \%)$ & $62(71.30 \%)$ & 0.0001 \\
\hline 6 & Correctly identified FH prevalence & $21(12.40 \%)$ & $12(14.50 \%)$ & $9(10.30 \%)$ & 0.281 \\
\hline 7 & Correctly identified FH inheritance & $74(43.50 \%)$ & $23(27.70 \%)$ & $51(58.60 \%)$ & 0.0001 \\
\hline 8 & Correctly identified CAD risk in $\mathrm{FH}$ & $12(7.10 \%)$ & $5(6.00 \%)$ & $7(8.00 \%)$ & 0.416 \\
\hline 11 & $\begin{array}{l}\text { Correctly identified that genetic test is not required for } \\
\text { accurate FH diagnosis }\end{array}$ & $78(45.90 \%)$ & $33(39.80 \%)$ & $45(51.70 \%)$ & 0.079 \\
\hline 22 & Correctly identified target LDL-c level in $\mathrm{FH}$ & $8(4.70 \%)$ & $5(6.00 \%)$ & $3(3.40 \%)$ & 0.334 \\
\hline \multirow[t]{7}{*}{23} & $\begin{array}{l}\text { Correctly selected family history of premature CAD to } \\
\text { be taken in FH }\end{array}$ & & & & \\
\hline & Consanguinity & $49(28.80 \%)$ & $27(32.50 \%)$ & $22(25.30 \%)$ & 0.191 \\
\hline & Family history of premature CHD (age of onset) & $106(62.40 \%)$ & $38(45.80 \%)$ & $68(78.20 \%)$ & 0.0001 \\
\hline & Family history of hypercholesterolaemia (TC and/ or LDL-C) & $89(52.40 \%)$ & $37(44.60 \%)$ & $52(59.80 \%)$ & 0.034 \\
\hline & Family history of tendon xanthomata & $76(44.70 \%)$ & $26(31.30 \%)$ & $50(57.50 \%)$ & 0.0001 \\
\hline & Family history of childhood unexplained death & $73(42.90 \%)$ & $17(20.50 \%)$ & $56(64.40 \%)$ & 0.0001 \\
\hline & Three-generation pedigree chart & $19(11.20 \%)$ & $11(13.30 \%)$ & $8(9.20 \%)$ & 0.276 \\
\hline 24 & $\begin{array}{l}\text { Correctly responded that none of the features given would } \\
\text { lead to exclusion of FH diagnosis }\end{array}$ & $170(100.00 \%)$ & $83(100.00 \%)$ & $87(100.00 \%)$ & - \\
\hline \multirow[t]{7}{*}{25} & $\begin{array}{l}\text { Correctly identified that combined statin with ezetimibe is } \\
\text { recommended for adult HeFH }\end{array}$ & & & & \\
\hline & $\begin{array}{l}\text { Ezetimibe co-administered with statin therapy is recommended } \\
\text { as an option for adult heterozygous FH }\end{array}$ & $64(37.60 \%)$ & $26(31.30 \%)$ & $38(43.70 \%)$ & 0.066 \\
\hline & Lipid lowering drug therapy is considered by the age of 10 years & $17(10.00 \%)$ & $9(10.80 \%)$ & $8(9.20 \%)$ & 0.459 \\
\hline & Progress of cascade screening in FH patients should be recorded & $13(7.60 \%)$ & $5(6.00 \%)$ & $8(9.20 \%)$ & 0.314 \\
\hline & Overall knowledge of FH (Total Score 17) & $\begin{array}{l}6.40 \pm 3.01 \\
(1.00-12.00)\end{array}$ & $\begin{array}{l}5.29 \pm 2.63 \\
(1.00-12.00)\end{array}$ & $\begin{array}{l}7.46 \pm 2.98 \\
(1.00-12.00)\end{array}$ & 0.0001 \\
\hline & Acceptable knowledge ( $\geq 9.5$ ) & $35(20.60 \%)$ & $6(7.20 \%)$ & $29(33.30 \%)$ & 0.0001 \\
\hline & Poor knowledge $(<9.5)$ & $135(79.40 \%)$ & $77(92.80 \%)$ & $58(66.70 \%)$ & 0.102 \\
\hline
\end{tabular}

FH: familial hypercholesterolemia. Data are expressed as mean+/- standard deviation (minimum - maximum) or number (\%) as appropriate. Comparison between male and female was made using Chi-Square test for non - parametric parameters and Mann Whitney test for parametric parameters. A mean knowledge score was computed by summing correct answers to all 11 knowledge questions. The knowlege regarding FH was considered acceptable if the total score was $\geq 50 \%$ 
presence of consanguinity, $11.2 \%$ select completion of three-generation pedigree chart. Regarding correctly answered that both together statin and ezetimibe is highly advocated for adult $\mathrm{HeFH}, 37.6 \%$ selected Ezetimibe co-administered with statin therapy is recommended as an option for adult heterozygous $\mathrm{FH}$, $10.0 \%$ select lipid lowering drug therapy is considered by the age of 10 years, $7.6 \%$ select the progress of cascade screening in $\mathrm{FH}$ patients should be recorded. The percentage of the female was significantly higher than male in many of the corrected answers Table 1. The mean total score of knowledge was 6.4 and was significantly higher in females than males $(7.5 \pm 3.0$ versus $5.3 \pm 2.6, P=0.0001)$. Only $20.6 \%$ had acceptable knowledge of $\mathrm{FH}$ while $79.4 \%$ of the participants had poor knowledge. The number of females who possess acceptable knowledge was significantly higher than males $(P=0.0001)$, meanwhile, insignificant difference between males and females with poor knowledge $(P=0.102)$.

\section{Awareness regarding $\mathrm{FH}$}

The numbers of correct answers to awareness items are stratified to male and female and are shown in Table 3. $54.1 \%$ are familiar with $\mathrm{FH}, 50.6 \%$ are aware of lipid clinics. Regarding awareness of guidelines; 16.5, 15.3, 9.4, 6.5, 5.9\% were acquainted with NICE recommendation, European Atherosclerosis Society Position Paper, International FH Foundation, National Lipid Association and The Japanese recommendations for the Management of $\mathrm{FH}$, respectively.

Regarding diagnostic criteria, 12.9, 7.1, 6.5, 4.7\% were familiar with Dutch Lipid Clinic Network Criteria, Simon Broome Register Criteria, US MEDPED Criteria, and The Japanese Criteria, respectively.

While, females were more aware of lipid clinics $(P=$ 0.0001 ), males were significantly higher than females in adopting international $\mathrm{FH}$ guidelines and are aware of FH diagnostic criteria. Unfortunately, all participants had poor overall awareness of FH (Table 3).

Table 3 Comparison of overall correct responses in awareness regarding FH between male and female Saudi medical interns. (5 questions, total score 11)

\begin{tabular}{|c|c|c|c|c|c|}
\hline No & Areas of KAP regarding $\mathrm{FH}$ being tested & $\begin{array}{l}\text { Total } \\
(n=170)\end{array}$ & $\begin{array}{l}\text { Male } \\
(n=83)\end{array}$ & $\begin{array}{l}\text { Female } \\
(n=87)\end{array}$ & $P$ value \\
\hline \multicolumn{6}{|c|}{ Awareness items } \\
\hline 1 & Familiar with FH & $92(54.10 \%)$ & $41(49.40 \%)$ & $51(58.60 \%)$ & 0.146 \\
\hline 2 & Aware of NICE Guideline on FH & $28(16.50 \%)$ & $13(15.70 \%)$ & $15(17.20 \%)$ & 0.472 \\
\hline 15 & Aware of lipid specialist clinic & $86(50.60 \%)$ & $28(33.70 \%)$ & $58(66.70 \%)$ & 0.0001 \\
\hline \multirow[t]{6}{*}{19} & Aware of other international FH guidelines & & & & \\
\hline & $\begin{array}{l}\text { Integrated Guidance on the Care of Familial Hypercholesterolaemia } \\
\text { by the International FH Foundation (2014) }\end{array}$ & $16(9.40 \%)$ & $12(14.50 \%)$ & $4(4.60 \%)$ & 0.025 \\
\hline & $\begin{array}{l}\text { Homozygous Familial Hypercholesterolaemia: New Insight and Guidance } \\
\text { for Clinicians to improve Detection and Clinical Management. A Position } \\
\text { Paper from the Consensus Panel on Familial Hypercholesterolaemia of } \\
\text { the European Atherosclerosis Society (EAS) (2014) }\end{array}$ & $26(15.30 \%)$ & $21(25.30 \%)$ & $5(5.70 \%)$ & 0.0001 \\
\hline & $\begin{array}{l}\text { The Japanese Guidelines for the Management of Familial } \\
\text { Hypercholesterolemia (Harada-Shiba, 2012) }\end{array}$ & $10(5.90 \%)$ & 9 (10.80\%) & $1(1.10 \%)$ & 0.007 \\
\hline & $\begin{array}{l}\text { Clinical Guidance by the National Lipid Association (NLA) } \\
\text { Expert Panel on Familial Hypercholesterolaemia (2011) }\end{array}$ & $11(6.50 \%)$ & $10(12.00 \%)$ & $1(1.10 \%)$ & 0.004 \\
\hline & Others & $0(0.00 \%)$ & $0(0.00 \%)$ & $0(0.00 \%)$ & 1.000 \\
\hline \multirow[t]{8}{*}{20} & Aware of FH diagnostic criteria & & & & \\
\hline & Dutch Lipid Clinic Network Criteria & $22(12.90 \%)$ & $17(20.50 \%)$ & $5(5.70 \%)$ & 0.004 \\
\hline & Simon Broome Register Criteria & $12(7.10 \%)$ & $11(13.30 \%)$ & $1(1.10 \%)$ & 0.002 \\
\hline & US MED-PED Criteria & $11(6.50 \%)$ & $8(9.80 \%)$ & $3(3.40 \%)$ & 0.091 \\
\hline & Japanese Criteria & $8(4.70 \%)$ & $7(8.40 \%)$ & $1(1.10 \%)$ & 0.027 \\
\hline & Others & $0(0.00 \%)$ & $0(0.00 \%)$ & $0(0.00 \%)$ & 1.000 \\
\hline & Overall awareness of FH (total score 13) & $\begin{array}{l}1.89 \pm 1.63 \\
(0.00-6.00)\end{array}$ & $\begin{array}{l}2.13 \pm 1.52 \\
(0.00-6.00)\end{array}$ & $\begin{array}{l}1.67 \pm 1.16 \\
(0.00-6.00)\end{array}$ & 0.068 \\
\hline & Poor awareness (< 7.5) & $170(100.00 \%)$ & $83(100.00 \%)$ & $87(100.00 \%)$ & 1.000 \\
\hline
\end{tabular}

FH: familial hypercholesterolemia. Data are expressed as mean+/- standard deviation (minimum - maximum) or number (\%) as appropriate. Comparison between male and female was made using Chi-Square test for non - parametric parameters and Mann Whitney test for parametric parameters. A mean awareness score was computed by summing correct answers to all 5 awareness questions. The awareness regarding FH was considered acceptable if the total score was $\geq 50 \%$ 


\section{Practice regarding $\mathrm{FH}$}

The numbers of correct answers to Practice items are stratified to male and female and are shown in Table 4. $82.9 \%$ selected statin to treat hypercholesterolemia, $62.9 \%$ routinely screened family members in FH diagnosed patients, $38.8 \%$ selected statin and ezetimibe combination for severe hypercholesterolemia treatment, $15.3 \%$ chose the age range in-between 13 to 18 years old to investigate for hypercholesterolemia if they had a positive family history of premature CAD.

The corrected responses of all participants in regard to screening the families of $\mathrm{FH}$ patients, were 26.5, 24.7, $20.6,14.7 \%$ by taking a detailed family history of CAD, looking for tendon xanthomata, screening close relatives for hypercholesterolemia, and looking for arcus cornealis, respectively.

The total score of the practice was 2.86 out of 8 and there was an insignificant difference between male and female $(2.86 \pm 1.9$ versus $2.9 \pm 1.9, P=0.846)$. In all participants, $14.7 \%$ had acceptable practice, while $85.3 \%$ had a poor practice of FH (Table 4).

\section{Opinion about health care providers}

Regarding opinion about health care providers that would be most useful in early FH detection and screening first-degree relative revealed that most of our intern doctors select GPs (60\%) followed by lipid specialists, endocrinologists, cardiologists, pediatricians, Obstetricians/ Gynecologists and lastly nurses with experience in cardiac risk prevention $(11.8,10.6,10.6,4.7,1.8,0.6 \%$, respectively) (Table 5).

\section{Discussion}

Cardiovascular diseases are the main cause of mortality and disease burden all over the world [25]. Medical intern doctors are in a good position to detect undiagnosed FH cases due to their first encounter with the patients without the intricacy of a busy routine practice. The high consanguinity rates in Arabian Gulf (Saudi Arabia, United Arab Emirates, Oman, Kuwait, Qatar) (up to 50\%) [26] and absence of national registries and screening programs [15] suggests that $\mathrm{FH}$ prevalence may be more than what is reported. Therefore, a crossnational Gulf FH-Registry began in February 2017. This initiative supported the opening of lipid clinics and lipoprotein apheresis centers. Sadly, only $13 \%$ of cases with acute coronary syndrome get LDL-C less than $70 \mathrm{mg} / \mathrm{dL}$ (Gulf-COAST registry) indicating a gap in medical knowledge and practice [27].

Unfortunately, this survey revealed that only $20.6 \%$ of medical interns had acceptable FH knowledge. Acceptable knowledge was reported in $\mathrm{FH}$ description (76.5\%) and lipid profile that diagnosed $\mathrm{FH}(52.4 \%)$. This is in accordance with previous researches among primary care physicians (PCP) who rightly define $\mathrm{FH}$ and know FH specific lipid levels in Malaysian (61.6 and 77.7\%) [28], Western Australia (80 and 68\%) [22], United Kingdom (89 and 74\%) [29] and Asia Pacific areas (86

Table 4 Comparison of overall correct responses in practice regarding FH between male and female Saudi medical interns. (5 questions, total score 8)

\begin{tabular}{|c|c|c|c|c|c|}
\hline No & Areas of KAP regarding $\mathrm{FH}$ being tested & $\begin{array}{l}\text { Total } \\
(n=170)\end{array}$ & $\begin{array}{l}\text { Male } \\
(n=83)\end{array}$ & $\begin{array}{l}\text { Female } \\
(n=87)\end{array}$ & $P$ value \\
\hline \multicolumn{6}{|c|}{ Practice items } \\
\hline \multirow[t]{5}{*}{10} & $\begin{array}{l}\text { Screened premature CAD patients for FH including } \\
\text { screening the family }\end{array}$ & & & & \\
\hline & Look for arcus cornealis & $25(14.70 \%)$ & $16(19.30 \%)$ & $9(10.30 \%)$ & 0.076 \\
\hline & Look for tendon xanthomata & $42(24.70 \%$ & $25(30.10 \%)$ & $17(19.50 \%)$ & 0.078 \\
\hline & Take a detailed family history of coronary heart disease & $45(26.50 \%)$ & $25(30.10 \%)$ & $20(23.00 \%)$ & 0.190 \\
\hline & Screen close relatives for hypercholesterolaemia & $35(20.60 \%)$ & $20(24.10 \%)$ & $15(17.20 \%)$ & 0.180 \\
\hline 12 & Routinely screened family in FH patient & $107(62.90 \%)$ & $40(48.20 \%)$ & $67(77.00 \%)$ & 0.0001 \\
\hline 14 & $\begin{array}{l}\text { Selected age } 13-18 \text { years to test young individuals for } \\
\text { hypercholesterolaemia if they have family history of } \\
\text { premature CAD }\end{array}$ & $26(15.30 \%)$ & $18(21.70 \%)$ & $8(9.20 \%)$ & 0.020 \\
\hline 17 & Selected statin to treat hypercholesterolaemia & $141(82.90 \%)$ & $62(74.70 \%)$ & $79(90.80 \%)$ & 0.005 \\
\hline \multirow[t]{4}{*}{18} & $\begin{array}{l}\text { Selected combination of statin and ezetimibe for treatment } \\
\text { of severe hypercholesterolaemia }\end{array}$ & $66(38.80 \%)$ & $31(37.30 \%)$ & $35(40.20 \%)$ & 0.410 \\
\hline & Overall practices of FH (Total Score 8) & $2.86 \pm 1.71(0.00-8.00)$ & $2.86 \pm 1.85(0.00-8.00)$ & $2.87 \pm 1.85(0.00-8.00)$ & 0.846 \\
\hline & Acceptable practice ( $\geq 4.5$ ) & $25(14.70 \%)$ & $13(15.70 \%)$ & $12(13.80 \%)$ & 0.841 \\
\hline & Poor practice $(<4.5)$ & $145(85.30 \%)$ & $70(84.30 \%)$ & $85(86.20 \%)$ & 0.678 \\
\hline
\end{tabular}

FH: familial hypercholesterolemia. Data are expressed as mean+/- standard deviation (minimum - maximum) or number (\%) as appropriate. Comparison between male and female was made using Chi-Square test for non - parametric parameters and Mann Whitney test for parametric parameters. A mean practice score was computed by summing correct answers to all 6 practice questions. The practice regarding FH was considered acceptable if the total score was $\geq 50 \%$ 
Table 5 Opinion about health care providers would be most effective at early detection of FH and screening first-degree relatives

\begin{tabular}{|c|c|c|c|c|}
\hline Areas of KAP regarding $\mathrm{FH}$ being tested & $\begin{array}{l}\text { Total } \\
(n=170)\end{array}$ & $\begin{array}{l}\text { Male } \\
(n=83)\end{array}$ & $\begin{array}{l}\text { Female } \\
(n=87)\end{array}$ & $P$-value \\
\hline General practitioners & $102(60.00 \%)$ & $32(38.60 \%)$ & $70(60.00 \%)$ & 0.001 \\
\hline Lipid specialists & $20(11.80 \%)$ & $15(18.10 \%)$ & $5(5.70 \%)$ & 0.025 \\
\hline Endocrinologists & $18(10.60 \%)$ & $13(15.70 \%)$ & $5(5.70 \%)$ & 0.059 \\
\hline Cardiologists & $18(10.60 \%)$ & $11(13.30 \%)$ & $7(8.00 \%)$ & 0.346 \\
\hline Pediatricians & $8(4.70 \%)$ & $8(9.60 \%)$ & - & - \\
\hline Obstetricians/ Gynecologists & $3(1.80 \%)$ & $3(3.60 \%)$ & - & - \\
\hline Nurses with experience in cardiac risk prevention & $1(0.60 \%)$ & $1(1.20 \%)$ & - & - \\
\hline
\end{tabular}

Data was expressed as number (\%). Comparison between male and female was made using Chi-Square test

and 65\%) [24]. On the contrary, a decreased number of $\mathrm{PCP}$ in Southern India accurately define $\mathrm{FH}$ and know specific lipid levels (71 and 35\%) [30].

The medical interns in this study had poor knowledge regarding global $\mathrm{FH}$ prevalence (12.4\%), inheritance (43.5\%), CAD risk (7.1\%), genetic test (45.9\%), target LDL-C reduction following maximum tolerance dose of high-intensity statin for diagnosed FH patients (4.7\%), important knowledge obtained from family history in FH patients as consanguinity (28.8\%), tendon xanthomata (44.7\%), unexplained death (42.9\%), threegeneration pedigree chart (11.2\%) and also poor knowledge regarding $\mathrm{FH}$ patients management options (37.6\%), giving lipid-lowering drug therapy by age of 10 years $(10.0 \%)$, recommendation of cascade screening progression in $\mathrm{FH}$ patients (7.6\%). Many studies reported physicians' FH-KAP to be suboptimal [22, 29-31]. In Malaysia, among 193 PCP, only 23.8, 66.8, and 40.4\% gave correct answers to global prevalence, FH clinical features, and transmission rate to first degree relatives, respectively [32]. Identification of the pattern of $\mathrm{FH}$ inheritance among physicians was $47 \%$ in Asia [31], 50.50\% in UK [29] and 33\% in Riyadh, Saudi Arabia [23]. The most concerning is PCP capability to know high CAD hazard in untreated $\mathrm{FH}$ was only $8.3 \%$ respond rightly in Malaysian [28], 9\% in Asia Pacific region [24], $14 \%$ in UK [22], $14 \%$ in Southern India [30] and 29\% in Western Australia [29]. This may be explained partially by the under-detection of $\mathrm{FH}$ patients.

International roles marked $\mathrm{FH}$ patients as possess elevated cardiovascular hazards; so, optimal LDL-C goal must be $<2.5 \mathrm{mmol} / \mathrm{L}$ or $<1.8 \mathrm{mmol} / \mathrm{L}$ with proven atherosclerotic CVD or at least a $50 \%$ decrement in LDL-C values $[8,33]$. In this study, only $4.7 \%$ of Saudi medical interns were oriented with optimal LDL-C values of FH patients. In this respect, over half of physicians in Batais et al. [23] study among 294 physicians in four big hospitals in Riyadh, Saudi Arabia was not known LDL-C values of $\mathrm{FH}$ cases. In Centralized Pan-Middle East Survey (CEPHEUS) that was made in 6 Persian Gulf regions, $52 \%$ of cases get their LDL-C targets [34]. There is poor adherence of the physicians to general dyslipidemia recommendations [35].

Early therapy must be initiated in FH cases, as they possess about 20-fold more hazards of getting premature CAD [36]. In this study, only 7.1\% know that CVD hazard in unmanaged $\mathrm{FH}$ cases as 20 times more compared to general people. In Batais et al. [23] survey among physicians in Riyadh, Saudi Arabia, $>90 \%$ of physicians were fit to detect CVD hazard in unmanaged $\mathrm{FH}$ individuals as 20 times more than general peoples, but were unable to know the age threshold for premature CAD in male and female.

Good family history is essential to CVD hazard check among FH. Pang et al. [24] reported that $90 \%$ of PCPs took complete family history in premature CAD cases. European roles propose checking children in FH kindred from 5 years old age [37] and NICE instructions advocate checking children between 2 and 10 years, PCPs in Asia-Pacific area suggested screening between 13 and 18 years old more convenient [24].

In this study, the percentage of the female were higher than male in many of the answers related to knowledge questions in defining $\mathrm{FH}$, lipid profile, $\mathrm{FH}$ inheritance, family history of premature CHD (age of onset), family history of hypercholesterolemia (TC and/ or LDL-C), positive family history of tendon xanthomata, and family history of childhood unexplained death. The mean of the total score of knowledge was significantly higher in females than males. This finding can partially be explained by elevated GPA score of females than males in the undergraduate years as well as the teaching setting is been conducted in independent campuses and independent staff for each gender, so the knowledge they acquired may vary. Batais et al. [24] found that FH knowledge scores more between physicians with longer duration in practice and those managed FH cases. These results suggested that future physicians' training may improve their ability to effectively treated $\mathrm{FH}$.

Unfortunately, all Saudi medical interns (100.0\%) had poor awareness about FH. Acceptable awareness was only reported about familiarity with $\mathrm{FH}(54.1 \%)$ and 
awareness of lipid specialist clinic (50.6\%). Meanwhile, the awareness gap was reported regarding international FH guidelines and FH diagnostic criteria. In this study, the correct response was higher in female than male in awareness of lipid specialist clinic, while, awareness was lower in female than male of other international $\mathrm{FH}$ roles and FH diagnostic criteria. There are several causes of this poor awareness. The clinical symptoms and signs of FH are not common; a family history of raised LDL-C is difficult to detect. The diagnostic criteria for $\mathrm{FH}$ rely on Dutch Lipid Clinics Network or Simon Broome criteria [38], might had been taught in medical school but were quickly forgotten [39]. The poor awareness of guidelines and lipid specialists can be due to the absence of country-specific guidelines [40] on $\mathrm{FH}$ and the poor training of physicians in the field of clinical Lipidology.

Many criteria are present to screen FH cases, as Make Early Diagnosis to Prevent Early Death [41], Simon Broome [42], DLCN criteria [43], US MED-PED criteria and Japanese criteria [44]. While, these methods could help to discover $\mathrm{FH}$ individuals, the DLCN guidelines commonly used due to their higher sensitivity $[33,45]$. Genetic testing could be used in FH diagnosis and to determine the type of $\mathrm{FH}$ (heterozygous or homozygous) [46]. In Malaysia, decrease awareness $(<20 \%)$ between PCP of different clinical algorithm methods was found with $25.9 \%$ know of cascade checking for FH cases [23]. In another study in Malaysia, defects were present in awareness of FH clinical guidelines between PCP. Less than half of the participants were aware of NICE roles (39\%) and their awareness of other international $\mathrm{FH}$ roles was less (19.1\%) and $72.8 \%$ of Malaysian PCP were unaware of $\mathrm{FH}$ diagnostic stigmata [28]. In the UK, $43.5 \%$ of physicians were aware of Simon Broome diagnostic stigmata and $65.9 \%$ were aware that family cascade checking is needed by NICE instructions [29], 61\% of PCP was aware of NICE instructions on FH [24]. This is very important as cascade checking of first-degree relatives of FH individuals is proven to be the most costreliable way to discover undetectable FH patients [47].

The results of this study revealed that acceptable practice was reported in only $14.7 \%$ of Saudi medical interns. The acceptable practice was found in a routine check of FH patient's close relatives with a lipid status (62.9\%), selection of statin to treat hypercholesterolemia (82.9\%). While, the poor practice was reported in family checking of $\mathrm{FH}$ in patients with documented premature CAD, the age for FH checking in young individuals for hypercholesterolemia in a family with premature CAD (15.3\%), selected both statin and ezetimibe together for therapy of severe hypercholesterolemia (38.8\%). In this study, the correct response of the female was higher than male in routinely check family in $\mathrm{FH}$ patient, selection of statin to treat hypercholesterolemia. While the correct answers of the male were higher than female in selection age 1318 years to check young individuals for hypercholesterolemia with a positive family history of premature CAD. The treatment aim in $\mathrm{FH}$ children, the European consensus on $\mathrm{FH}$ recommends in children LDL-C $<135 \mathrm{mg} /$ $\mathrm{dL}(\approx 3.5 \mathrm{mmol} / \mathrm{L})$ as aim in both heterozygous and homozygous $\mathrm{FH}$, irrespective of age [48]. The presence of very high LDL-C or more cardiovascular risk factors may decrease this target level or the starting age of therapy with statin. In FH children such a target value is hard to reach with available cholesterol-lowering drugs. So, much is expected from the agents against PCSK9, antisense oligonucleotides against apolipoprotein B, microsomal triglyceride transfer protein suppressors, and so on to reduce LDL-C below levels obtained with statin alone [49]. The long-term safety and efficacy results of trials with these medications in children are still under trial [50]. The International FH Foundation offers guidance on FH treatment [33]. These systemic guidelines were lodged as an excellent method for the creation of MENA FH registry [15]. In countries with a history of dedicated checking programs, as Netherlands and Norway, the outcomes in terms of newly diagnosed FH index cases and cascade tested relatives were higher than countries lacking any formal checking program (usually< $<$ \%) $[8,51]$.

Dissimilarity in the selection of healthcare professional recognized as a better place for treating $\mathrm{FH}$ and family checking between different areas might indicate, unlike healthcare programs. In this survey, most medical intern doctors choose GP $(60 \%)$ as the most effective health care providers to consult rather than lipid specialists (11.8\%), endocrinologists (10.6\%), cardiologists (10.6\%), pediatricians (4.7\%), Obstetricians/ Gynecologists (1.8\%) and lastly nurses with experience in cardiac risk prevention (0.6\%). In Malaysia, the majority of PCP (85.2\%) choose themselves as most beneficial healthcare donors in rapid FH diagnosis and family check [28]. In China, most of PCP (83\%) think that lipid specialists were best to manage FH [24]. Others view that cardiologists are well-positioned to identify $\mathrm{FH}$ cases presenting with coronary artery diseases [37]. Endocrinologists were thought to be in a good position to detect $\mathrm{FH}$ in secondary prevention settings [24]. However, due to the large number of GPs in Saudi Arabia it makes perfect sense that they should be consulted first giving that they acquire the proper training well and the complex cases should be referred to lipidologist in other to specialty. Little suggests an important role for nurses [24] which can be explained by the lack of nurses practitioner in this field. This differs from Netherlands [52] results were screening programs have been applied by allied health members and/or nursing. Screening may also be made in a non-medical place as schools and workplaces; this 
option was not checked in this work. Further detection of health services and systems are needed to optimize country-special clinical service models and care integration [33]. Primary care plays an important role but the absence of infrastructure and supports offered by hospital lipid clinics. Such support will be important if a sustainable primary care-based model of care is established [53].

\section{Strength and limitation of this study}

The strength of this research was the utilization of a validated FH-KAP questionnaire. This study added novel information in the areas of medical education, and included a significant difference between male and female FH-KAP scores that might be a reflection of the medical education system style. This work is limited due to the nature of survey based research and the results cannot proof or disproof causality, where results showed relations and not certainly causal association. Also, medical interns were from two academic institutes in Jeddah, and therefore the results may not be generalized. However, no similar research was made on medical interns and so these results are generally interesting and of great value to improve the medical education system. Another restriction of the present work was that other CVD hazard factors were not surveyed like; hypertension, type 2 diabetes mellitus, obesity and smoking, especially with the rising incidence of risk factors in the Middle East [54].

\section{Conclusion and recommendations}

Our survey suggested that there is a deficit in knowledge, awareness, and practice about FH among Saudi medical interns at King Abdulaziz University and University of Jeddah graduates. Overall, Saudi medical interns had good knowledge in the definition of $\mathrm{FH}$ and knowing FH lipid status, familial pattern, aware of lipid specialist clinic and treatment with a statin. However, substantial gaps were found in many items of FH care as knowledge about prevalence, mode of inheritance and CAD hazard factors, genetic test, LDL-C level, premature CAD family history, awareness of clinical roles and characteristics of diagnosis, as well as practice on CAD hazard stratification, FH cases screened family. Female Saudi medical interns had better knowledge regarding $\mathrm{FH}$ than males while the male had better awareness aspects than female. Nevertheless, both genders had a low score level of FH-KAP. Our findings support the need for the development of Saudi clinical guidelines for FH management. There is a need for enhancing FH and related lipid topics in medical curricula and restructuring continuing medical education activities at teaching hospitals aimed at medical intern doctors. These strategies can improve the care and detection of $\mathrm{FH}$ and decrease the burden of premature CAD.

\section{Abbreviations}

FH: Familial Hypercholesterolemia; LDL-C: Low-density lipoprotein cholesterol; CAD: Premature coronary artery diseases; MI: Myocardial infarction; LDLR: Low-density lipoprotein receptor; AD: Autosomal dominant; AR: Autosomal recessive; PCSK9: Proprotein convertase subtilisin/ Kexin type 9; APOB: Apolipoprotein B-100; HeFH: Heterozygous FH; HoFH: Homozygous FH; LDLRAP1: LDL receptor adaptor protein 1; MENA: Middle Eastern and North African; FH-KAP: Knowledge, awareness, and practice in $\mathrm{FH}$

\section{Acknowledgements}

We are thankful to administration of King Abdulaziz University hospital for their support during the data collection for this article.

\section{Authors' contributions}

SH carried the study design, statistical analyses and shared in introduction and discussion writing. AB Logistics shared in writing results, discussion and gathered references. MA data collection, data entry, validation, and coding, shared in writing introduction, discussion and gathered references. ZA Logistics, interpretation and writing of results and discussion, review and final approval of manuscript. The author(s) read and approved the final manuscript.

\section{Funding}

This research was funded by the Deanship of Scientific Research (DSR), King Abdulaziz University, Jeddah, Saudi Arabia.

\section{Availability of data and materials}

All original data is available in the Department of Family Medicine, King Abdulaziz University, Jeddah, Saudi Arabia.

\section{Ethics approval and consent to participate}

The protocol of the present study was approved by the Research Ethics Committee (REC) of King Abdulaziz University, Jeddah, Saudi Arabia. (Reference No. 003974). Written informed consent was obtained and documented from all participants. They were informed about the nature of the study and confidentiality of their response.

\section{Consent for publication}

Not applicable.

\section{Competing interests}

The authors declare that they have no financial and Non-financial competing interests.

\section{Author details}

${ }^{1}$ Family Medicine Department, Faculty of Medicine, King Abdulaziz University, PO Box 80205, Jeddah 21589, Saudi Arabia. ${ }^{2}$ Clinical Biochemistry Department, Faculty of Medicine, King Abdulaziz University, Jeddah, Saudi Arabia. ${ }^{3}$ King Abdulaziz University Hospital, Jeddah, Saudi Arabia.

Received: 5 January 2020 Accepted: 22 April 2020

Published online: 21 May 2020

\section{References}

1. Müller C. Xanthomata, hypercholesterolemia, angina pectoris. Acta Medica Scandinavica. 1938;95:75-84

2. Brown MS, Goldstein JL. Expression of the familial hypercholesterolemia gene in heterozygotes: mechanism for a dominant disorder in man. Science. 1974;185:61-3.

3. Marks D, Thorogood M, Neil HAW, Humphries SE. A review on the diagnosis, natural history, and treatment of familial hypercholesterolaemia. Atherosclerosis. 2003;168:1-14.

4. Abifadel M, Varret M, Rabès J-P, Allard D, Ouguerram K, Devillers M, Cruaud C, Benjannet S, Wickham L, Erlich D. Mutations in PCSK9 cause autosomal dominant hypercholesterolemia. Nat Genet. 2003;34:154-6.

5. Innerarity TL, Weisgraber KH, Arnold KS, Mahley RW, Krauss RM, Vega GL, Grundy SM. Familial defective apolipoprotein B-100: Iow density lipoproteins with abnormal receptor binding. Proc Natl Acad Sci. 1987;84:6919-23.

6. Garcia CK, Wilund K, Arca M, Zuliani G, Fellin R, Maioli M, Calandra S, Bertolini S, Cossu F, Grishin N. Autosomal recessive hypercholesterolemia caused by mutations in a putative LDL receptor adaptor protein. Science. 2001;292:1394-8. 
7. Filigheddu F, Quagliarini F, Campagna F, Secci T, Degortes S, Zaninello R, Argiolas G, Verna R, Pitzoi S, Frau F. Prevalence and clinical features of heterozygous carriers of autosomal recessive hypercholesterolemia in Sardinia. Atherosclerosis. 2009;207:162-7.

8. Nordestgaard B, Chapman M, Humphries S, Ginsberg H, Masana L, Descamps O, Wiklund O, Hegele R, Raal F, Defesche J. European Atherosclerosis Society Consensus Panel. Familial hypercholesterolaemia is underdiagnosed and undertreated in the general population: guidance for clinicians to prevent coronary heart disease: consensus statement of the European Atherosclerosis Society. Eur Heart J. 2013;34:3478-3490a.

9. Shi Z, Yuan B, Zhao D, Taylor AW, Lin J, Watts GF. Familial hypercholesterolemia in China: prevalence and evidence of underdetection and undertreatment in a community population. Int J Cardiol. 2014;174:834-6.

10. Watts GF, Shaw JE, Pang J, Magliano DJ, Jennings G, Carrington MJ. Prevalence and treatment of familial hypercholesterolaemia in Australian communities. Int J Cardiol. 2015;185:69.

11. Goldberg AC, Robinson JG, Cromwell WC, Ross JL, Ziajka PE. Future issues, public policy, and public awareness of familial hypercholesterolemias: recommendations from the National Lipid Association Expert Panel on Familial hypercholesterolemia. J Clin Lipidol. 2011;5:S46-51.

12. de Ferranti SD, Rodday AM, Mendelson MM, Wong JB, Leslie LK, Sheldrick RC. Prevalence of familial hypercholesterolemia in the 1999 to 2012 United States national health and nutrition examination surveys (NHANES). Circulation. 2016, 133:1067-72.

13. Alghamdi M, Aljohani E. Clinical outcome of familial hypercholesterolemia (FH) at king Abdulaziz Medical City, Riyadh-a 20 year experience. J Saudi Heart Assoc. 2013;25:149.

14. Alallaf F, Nazar FAH, Alnefaie M, Almaymuni A, Rashidi OM, Alhabib K, Alnouri F, Alama M-N, Athar M, Awan Z. The spectrum of familial hypercholesterolemia (FH) in Saudi Arabia: prime time for patient $\mathrm{FH}$ registry. Open Cardiovasc Med J. 2017;11:66.

15. Bamimore MA, Zaid A, Banerjee Y, Al-Sarraf A, Abifadel M, Seidah NG, AlWaili K, Al-Rasadi K, Awan Z. Familial hypercholesterolemia mutations in the middle eastern and north African region: a need for a national registry. J Clin Lipidol. 2015;9:187-94.

16. Dorsch MF, Lawrance RA, Durham NP. Hall AS. Familial hypercholesterolaemia is underdiagnosed after AMI. BMJ. 2001;322:111.

17. Reiner Ž. Management of patients with familial hypercholesterolaemia. Nat Rev Cardiol. 2015;12:565.

18. Santos RD, Gidding SS, Hegele RA, Cuchel MA, Barter PJ, Watts GF, Baum SJ, Catapano AL, Chapman MJ, Defesche JC. Defining severe familial hypercholesterolaemia and the implications for clinical management: a consensus statement from the international Atherosclerosis society severe Familial hypercholesterolemia panel. Lancet Diabetes Endocrinol. 2016;4:850-61.

19. Sjouke B, Kusters DM, Kindt I, Besseling J, Defesche JC, Sijbrands EJ, Roeters van Lennep JE, Stalenhoef AF, Wiegman A, de Graaf J. Homozygous autosomal dominant hypercholesterolaemia in the Netherlands: prevalence, genotype-phenotype relationship, and clinical outcome. Eur Heart J. 2015; 36:560-5.

20. Hattie J, Cooksey RW. Procedures for assessing the validities of tests using the" known-groups" method. Appl Psychol Meas. 1984;8:295-305.

21. Tan S. Misuses of KR-20 and Cronbach's alpha reliability coefficients. Egitim ve Bilim. 2009:34:101.

22. Bell DA, Garton-Smith J, Vickery A, Kirke AB, Pang J, Bates TR, Watts GF. Familial hypercholesterolaemia in primary care: knowledge and practices among general practitioners in Western Australia. Heart Lung Circ. 2014;23:309-13.

23. Batais MA, Almigbal TH, Abdulhak AAB, Altaradi HB, AlHabib KF. Assessment of physicians' awareness and knowledge of familial hypercholesterolemia in Saudi Arabia: is there a gap? PLoS One. 2017;12(8):e0183494.

24. Pang J, Hu M, Lin J, Miida T, Nawawi HM, Park JE, Wu X, Ramli AS, Kim NT, Gonzalez-Santos LE. An enquiry based on a standardised questionnaire into knowledge, awareness and preferences concerning the care of familial hypercholesterolaemia among primary care physicians in the Asia-Pacific region: the "ten countries study". BMJ Open. 2017;7:e017817.

25. Reiner Ž, Sonicki Z, Tedeschi-Reiner E. Physicians' perception, knowledge and awareness of cardiovascular risk factors and adherence to prevention guidelines: the PERCRO-DOC survey. Atherosclerosis. 2010; 213:598-603.

26. El-Hazmi M, Al-Swailem A, Warsy A, Al-Swailem A, Sulaimani R, Al-Meshari A. Consanguinity among the Saudi Arabian population. J Med Genet. 1995;32: 623-6.
27. Al-Rasadi K, Al-Zakwani I, Alsheikh-Ali AA, Almahmeed W, Rashed W, Ridha $M$, Santos RD, Zubaid M. Prevalence, management, and outcomes of familial hypercholesterolemia in patients with acute coronary syndromes in the Arabian Gulf. J Clin Lipidol. 2018;12:685-92 e682.

28. Azraii AB, Ramli AS, Ismail Z, Abdul-Razak S, Mohd-Kasim NA, Ali N, Watts GF, Nawawi H. Knowledge, awareness and practice regarding familial hypercholesterolaemia among primary care physicians in Malaysia: the importance of professional training. Atherosclerosis. 2018;277:508-16.

29. Schofield J, France M, Capps N, Eatough R, Yadav R, Ray K, Soran H. Knowledge gaps in the management of familial hypercholesterolaemia. A UK based survey. Atherosclerosis. 2016;252:161-5.

30. Rangarajan N, Balasubramanian S, Pang J, Watts GF. Knowledge and awareness of familial hypercholesterolaemia among registered medical practitioners in Tamil Nadu: are they suboptimal? J Clin Diagn Res. 2016;10:OC52.

31. Pang J, Sullivan DR, Harada-Shiba M, Ding PY, Selvey S, Ali S, Watts GF. Significant gaps in awareness of familial hypercholesterolemia among physicians in selected Asia-Pacific countries: a pilot study. J Clin Lipidol. 2015;9:42-8

32. Ramli A, Mokhsin NM, Razak SA, Yasin MM, Ismail Z, Kasim NM, Rahman T, Nawawi H. Familial hypercholesterolaemia in primary care: awareness, knowledge and practices among primary care doctors in Malaysia. Atherosclerosis. 2016;252:e41.

33. Watts GF, Sullivan DR, Poplawski N, Van Bockxmeer F, Hamilton-Craig I, Clifton PM, O'Brien R, Bishop W, George P, Barter PJ. Familial hypercholesterolaemia: a model of care for Australasia. Atheroscler Suppl. 2011;12:221-63.

34. Arafah M, Al-Hinai AT, Mahmeed WA, Al-Rasadi K, Tamimi OA, Herz SA, Anazi FA, Nemer KA, Metwally O, Alkhadra A. Centralized pan-Middle East survey on the undertreatment of hypercholesterolemia: results from the CEPHEUS study in Arabian gulf countries. Angiology. 2014;65:919-26.

35. Al Rasadi K, Almahmeed W, AlHabib KF, Abifadel M, Farhan HA, AlSifri S, Jambart S, Zubaid M, Awan Z, Al-Waili K. Dyslipidaemia in the Middle East: current status and a call for action. Atherosclerosis. 2016;252:182-7.

36. Gersh BJ, Sliwa K, Mayosi BM, Yusuf S. Novel therapeutic concepts the epidemic of cardiovascular disease in the developing world: global implications. Eur Heart J. 2010;31:642-8.

37. Wiegman A, Gidding SS, Watts GF, Chapman MJ, Ginsberg HN, Cuchel M, Ose L, Averna M, Boileau C, Borén J. Familial hypercholesterolaemia in children and adolescents: gaining decades of life by optimizing detection and treatment. Eur Heart J. 2015:36:2425-37.

38. Genest J, Hegele RA, Bergeron J, Brophy J, Carpentier A, Couture P, Davignon J, Dufour R, Frohlich J, Gaudet D. Canadian cardiovascular society position statement on familial hypercholesterolemia. Can J Cardiol. 2014;30:1471-81.

39. Genest J. Familial hypercholesterolemia: awareness, appraisal, and action. Can J Cardiol. 2017:33:298-9.

40. Zhou M, Zhao D. Familial hypercholesterolemia in Asian populations. J Atheroscler Thromb. 2016:34405-16.

41. Williams RR, Hunt SC, Schumacher MC, Hegele RA, Leppert MF, Ludwig EH, Hopkins PN. Diagnosing heterozygous familial hypercholesterolemia using new practical criteria validated by molecular genetics. Am J Cardiol. 1993;72:171-6.

42. Scientific Steering Committee on behalf of the Simon Broome Register Group. Risk of fatal coronary heart disease in familial hypercholesterolaemia. BMJ. 1991;303(6807):893-6. https://doi.org/10.1136/bmj.303.6807.893.

43. WHO H. Familial hypercholesterolemia: report of a second WHO consultation. Geneva: WHO; 1999.

44. Harada-Shiba M, Arai H, Oikawa S, Ohta T, Okada T, Okamura T, Nohara A, Bujo H, Yokote K, Wakatsuki A. Guidelines for the management of familial hypercholesterolemia. J Atheroscler Thromb. 2012;19:1043-60.

45. Familial H, Watts $G$, Sullivan D, Poplawski N, van Bockxmeer F, HamiltonCraig I, Clifton P, O'Brien R, Bishop W, George P. Familial Hypercholesterolaemia Australasia network (Australian Atherosclerosis society). Atherosclerosis-Amsterdam-Supplement. 2011;12:221-63.

46. Sullivan DR, Hamilton-Craig I, Van Bockxmeer F, Watts GF. INTERIM guidelines for the diagnosis and management of familial hypercholesterolaemia. Heart Lung Circ. 2012;21:159-62.

47. Gray J, Jaiyeola A, Whiting M, Modell M, Wierzbicki A. Identifying patients with familial hypercholesterolaemia in primary care: an informatics-based approach in one primary care Centre. Heart. 2008;94:754-8.

48. Nordestgaard BG, Chapman MJ, Humphries SE, Ginsberg HN, Masana L, Descamps OS, Wiklund O, Hegele RA, Raal FJ, Defesche JC. Familial 
hypercholesterolaemia is underdiagnosed and undertreated in the general population: guidance for clinicians to prevent coronary heart disease: consensus statement of the European Atherosclerosis society. Eur Heart J. 2013:34:3478-90.

49. Reiner Ž. Managing the residual cardiovascular disease risk associated with HDL-cholesterol and triglycerides in statin-treated patients: a clinical update. Nutr Metab Cardiovasc Dis. 2013;23:799-807.

50. Reiner Ž. Impact of early evidence of atherosclerotic changes on early treatment in children with familial hypercholesteremia. Am Heart Assoc. 2014;114(2):233-5.

51. Louter L, Defesche J, van Lennep JR. Cascade screening for familial hypercholesterolemia: practical consequences. Atheroscler Suppl. 2017;30: 77-85.

52. Umans-Eckenhausen MA, Defesche JC, Sijbrands EJ, Scheerder RL, Kastelein $\mathrm{JJ}$. Review of first 5 years of screening for familial hypercholesterolaemia in the Netherlands. Lancet. 2001;357:165-8.

53. Gidding SS, Ann Champagne M, de Ferranti SD, Defesche J, Ito MK, Knowles JW, McCrindle B, Raal F, Rader D, Santos RD. The agenda for familial hypercholesterolemia: a scientific statement from the American Heart Association. Circulation. 2015;132:2167-92.

54. Ahmed AM, Hersi A, Mashhoud W, Arafah MR, Abreu PC, Al Rowaily MA, AlMallah MH. Cardiovascular risk factors burden in Saudi Arabia: the Africa Middle East cardiovascular epidemiological (ACE) study. J Saudi Heart Assoc. 2017;29:235-43.

\section{Publisher's Note}

Springer Nature remains neutral with regard to jurisdictional claims in published maps and institutional affiliations.

Ready to submit your research? Choose BMC and benefit from:

- fast, convenient online submission

- thorough peer review by experienced researchers in your field

- rapid publication on acceptance

- support for research data, including large and complex data types

- gold Open Access which fosters wider collaboration and increased citations

- maximum visibility for your research: over $100 \mathrm{M}$ website views per year

At $\mathrm{BMC}$, research is always in progress.

Learn more biomedcentral.com/submissions 